\title{
Blimp-1 impairs T cell function via upregulation of TIGIT and PD-1 in patients with acute myeloid leukemia
}

Liuluan Zhu ${ }^{1,2+}$, Yaxian Kong ${ }^{1,2 \dagger}$, Jianhong Zhang ${ }^{2}$, David F. Claxton ${ }^{2}$, W. Christopher Ehmann ${ }^{2}$, Witold B. Rybka ${ }^{2}$, Neil D. Palmisiano ${ }^{3}$, Ming Wang ${ }^{4}$, Bei $\mathrm{Jia}^{2}$, Michael Bayerl ${ }^{5}$, Todd D. Schell ${ }^{2,6}$, Raymond J. Hohl2 ${ }^{2}$ Hui Zeng ${ }^{1 *}$ and Hong Zheng ${ }^{2,6^{*}}$ (D)

\begin{abstract}
Background: T cell immunoglobulin and immunoreceptor tyrosine-based inhibitory motif (ITIM) domain (TIGIT) and programmed cell death protein 1 (PD-1) are important inhibitory receptors that associate with T cell exhaustion in acute myeloid leukemia (AML). In this study, we aimed to determine the underlying transcriptional mechanisms regulating these inhibitory pathways. Specifically, we investigated the role of transcription factor B lymphocyte-induced maturation protein 1 (Blimp-1) in T cell response and transcriptional regulation of TIGIT and PD-1 in AML.

Methods: Peripheral blood samples collected from patients with AML were used in this study. Blimp-1 expression was examined by flow cytometry. The correlation of Blimp-1 expression to clinical characteristics of AML patients was analyzed. Phenotypic and functional studies of Blimp-1-expressing T cells were performed using flow cytometry-based assays. Luciferase reporter assays and ChIP assays were applied to assess direct binding and transcription activity of Blimp-1. Using siRNA to silence Blimp-1, we further elucidated the regulatory role of Blimp-1 in the TIGIT and PD-1 expression and $T$ cell immune response.
\end{abstract}

Results: Blimp-1 expression is elevated in T cells from AML patients. Consistent with exhaustion, Blimp-1 ${ }^{+} \mathrm{T}$ cells upregulate multiple inhibitory receptors including PD-1 and TIGIT. In addition, they are functionally impaired manifested by low cytokine production and decreased cytotoxicity capacity. Importantly, the functional defect is reversed by inhibition of Blimp-1 via siRNA knockdown. Furthermore, Blimp-1 binds to the promoters of PD-1 and TIGIT and positively regulates their expression.

Conclusions: Our study demonstrates an important inhibitory effect of Blimp-1 on T cell response in AML; thus, targeting Blimp-1 and its regulated molecules to improve the immune response may provide effective leukemia therapeutics.

Keywords: Blimp-1, TIGIT, PD-1, T cell exhaustion, Acute myeloid leukemia (AML)

\footnotetext{
* Correspondence: zenghui@ccmu.edu.cn; hzheng@pennstatehealth.psu.edu

†Equal contributors

${ }^{1}$ Institute of Infectious Diseases, Beijing Ditan Hospital, Beijing Key Laboratory

of Emerging Infectious Diseases, Capital Medical University, Beijing, China

${ }^{2}$ Penn State Cancer Institute, Penn State University College of Medicine,

Hershey, PA, USA

Full list of author information is available at the end of the article
} 


\section{Background}

Acute myeloid leukemia (AML) is the most common acute leukemia in adults with around 20,000 new diagnoses each year in the USA. The mainstream of treatment for AML is induction chemotherapy followed by post-remission consolidation. Allogeneic hematopoietic stem cell transplantation in many clinical settings can significantly improve survival. However, the overall prognosis remains poor with a 5 -year survival rate of only $25 \%$. Novel effective leukemia therapeutics is urgently needed.

Modulating the immune response to improve antitumor immunity provides a promising strategy for cancer treatment [1]. Studies using reagents inhibiting negative immune regulatory pathways, such as programmed cell death protein 1 (PD-1), have achieved great success [2-5]. This strategy targets $\mathrm{T}$ cell exhaustion, a status of $\mathrm{T}$ cell dysfunction that contributes to compromised anti-tumor $\mathrm{T}$ cell responses. Exhausted $\mathrm{T}$ cells gradually lose their capacity for cytokine production and cell killing, eventually undergo apoptosis and deletion [6]. Upregulation of PD-1 and other inhibitory pathways such as $\mathrm{T}$ cell immunoglobulin domain and mucin domain 3 (TIM-3), 2B4, Lymphocyte-activation gene 3 (LAG3 ), and $\mathrm{T}$ cell immunoglobulin and immunoreceptor tyrosine-based inhibitory motif (ITIM) domain (TIGIT) is not only a hallmark, but also an important mechanism involved in the development of $\mathrm{T}$ cell exhaustion [7-18]. Studying the role of inhibitory pathways in AML is appealing. Several reports including ours have shown that inhibitory receptors including PD-1, TIM-3, and TIGIT are elevated on T cells and associate with immune suppression in AML [19-26]. Combined blockade of PD-1 and TIM-3 pathways synergistically reduced tumor burden and leukemia death in a mouse model of AML [21]. These data suggest that targeting the inhibitory pathways to restore $\mathrm{T}$ cell function and anti-tumor immune response may represent an effective leukemia therapy. Moving this strategy forward to clinical applications is under active development, but it is also important to understand the transcriptional mechanisms involved in the regulation of these inhibitory receptors in AML, which is currently unknown.

B lymphocyte-induced maturation protein 1 (Blimp-1) is a zinc finger-containing transcription factor functioning as a decision maker for memory $B$ cell differentiation [27, 28]. Recent studies in mouse models of infection uncovered its crucial role in regulating $\mathrm{CD}^{+} \mathrm{T}$ cell exhaustion [29-31]. Here, we examine the effect of Blimp-1 in the pathogenesis of AML using blood samples collected from a cohort $(n=24)$ of patients with AML at initial diagnosis.
We demonstrate an inhibitory role for Blimp-1 on $\mathrm{T}$ cell response in AML. Elevated expression of Blimp1 in $\mathrm{T}$ cells associates with upregulation of inhibitory receptors and reduced $\mathrm{T}$ cell capacity of cytokine production and cytotoxicity, features which are consistent with exhaustion. Importantly, Blimp-1 knockdown by siRNA reverses these functional defects. In addition, Blimp-1 binds to the promoters of PD-1 and TIGIT and upregulates their expression, suggesting that the suppressive effect of Blimp-1 on the $\mathrm{T}$ cell response is mediated by its transcriptional regulation of PD-1 and TIGIT. Our studies demonstrate that Blimp-1 is an important regulator of $\mathrm{T}$ cell exhaustion in AML and thus an attractive target for effective leukemia therapeutics.

\section{Methods \\ Patients}

Peripheral blood collected from AML patients were obtained from the tissue bank maintained by the Penn State Hershey Cancer Institute of Penn State University College of Medicine, Hershey, PA. The study was approved by the Institutional Review Board of Penn State University College of Medicine. Full informed consent was obtained from all patients. Samples from 24 patients (10 males and 14 females, age $57 \pm 15$ years, range, 23-77 years) diagnosed with AML per WHO classification were used in the study. Samples of 25 healthy volunteers (13 males and 12 females, age $55 \pm 15$ years, range, 21-77 years) were obtained as controls.

\section{Immunofluorescence staining and flow cytometric analysis}

For surface staining, cells were incubated at room temperature with human Fc block (BD Biosciences, San Diego, CA, USA) and followed by staining with directly conjugated $\mathrm{mAbs}$ for $30 \mathrm{~min}$ at $4{ }^{\circ} \mathrm{C}$. The mAbs used were anti-human CD3-BV605, CD4-V500, CD8-APCH7, CD45RA-BV421, CCR7-PerCp-Cy5.5, PD-1-PE-Cy7, CD160-Alexa Fluor 488 (BD Biosciences), CD4-FITC, TIM-3-BV421, 2B4-PerCp-Cy5.5 (BioLegend, San Diego, CA, USA), and TIGIT-APC (eBioscience, San Diego, CA, USA). Data acquisition was performed on a LSR Fortessa flow cytometer (BD Biosciences). FlowJo Software (Tree Star, Ashland, OR, USA) was used in data analysis.

\section{SmartFlares}

Lyophilized SmartFlare probe (Merck Millipore, Guyancourt, France) was used to detect Blimp-1 mRNA following the manufacturer's instruction. 
In vitro stimulation and intracellular staining

PBMCs were stimulated with anti-CD3/CD28 (2 and $5 \mu \mathrm{g} / \mathrm{mL}$ ), plus Golgiplug (BD Pharmingen) for $5 \mathrm{~h}$ before intracellular staining Blimp-1-PE, IFN- $\gamma$-PE-CF594, and IL-2-PerCp-Cy5.5 (BD Pharmingen). For perforin study, perforin-PE-CF594 (BD Pharmingen) was used. A Fixable Viability Dye eFluor 450 (eBioscience) was used to assess cell viability.

\section{siRNA transfection}

SMARTpool of siRNA for Blimp-1 and control were obtained from GE Dharmacon RNA Technologies (GE Dharmacon, Lafayette, CO, USA). Control and specific siRNAs were added at a final concentration of $1 \mu \mathrm{M}$ per well for $72 \mathrm{~h}$. For functional assays, cells were further stimulated with anti-CD3/CD28 for $5 \mathrm{~h}$, followed by flow analysis.

\section{Plasmid construction, transfection, and real-time PCR}

PRDM1a plasmid (RGS-6xHis-BLIMP-1-pcDNA3.1-) was a gift from Adam Antebi [32]. PRDM1 $\beta$ cDNA was cloned into pcDNA3.1+ plasmid. The $P D-1$ gene promoter $(-1063 /+70 \mathrm{bp}$ relative to the transcription start site) and TIGIT promoter $(-2228 /+76 \mathrm{bp})$ were cloned into pGL3-basic. PRDM1 $\alpha$ and $P R D M 1 \beta$ plasmids were transfected using Lipofectamine 3000 (Thermo Fisher Scientific, Waltham, MA, USA). Specific transcripts were quantified by real-time PCR with TaqMan probes according to the manufacturer's instructions (Thermo Fisher Scientific).

\section{Luciferase reporter assay}

293T cells were transfected with a mixture of the indicated expression plasmids. After $24 \mathrm{~h}$, luciferase assays were performed using a dual-Luciferase Reporter Assay System (Promega, Madison, WI, USA) according to the manufacturer's instructions.

\section{Chromatin immunoprecipitation (ChIP) assay}

ChIP assays were conducted as previously described [33]. Briefly, $T$ cells were stimulated in vitro with anti-CD3 [34] for $48 \mathrm{~h}$ followed by cross-linking, sonication, and chromatin immunoprecipitation with antibodies to Blimp-1 or normal goat IgG (Abcam, Cambridge, UK). DNA was then quantified by realtime PCR. Primer sequences were provided in Additional file 1: Supplemental data.

\section{Statistical analysis}

GraphPad5 (GraphPad Software, La Jolla,CA, USA) was used for statistical calculations. The normality of each continuous variable was evaluated using the Kolmogorov-Smirnov test. For data distributed normally, the comparison of variables was performed using unpaired or paired (where specified) Student's $t$ test. For data not distributed normally, the comparison of variables was performed with a MannWhitney $U$ test or a Wilcoxon signed-rank test for unpaired and paired data, respectively. Comparisons of categorical patient characteristics were analyzed using Fisher's exact test. To evaluate correlation, Pearson's correlation coefficients were used. All tests are two-tailed with $P$ values less than 0.05 considered statistically significant.

\section{Results}

\section{Blimp-1 is upregulated in T cells from AML patients}

To determine the effect of Blimp-1 on the T cell response in patients with AML, we first assessed the expression of Blimp-1 mRNA in both $\mathrm{CD}^{+}$and CD8 + T cells. PBMCs collected from 24 AML patients at initial diagnosis were examined. Samples from 25 ageand gender-matched healthy donors (HD) served as controls. We used a novel technology, the SmartFlare system [35], to detect Blimp-1 mRNA by flow cytometry. Importantly, this nanoparticle-based system allows us to test the transcripts within individual living cells. We observed a significant elevation of Blimp-1 mRNA in both $\mathrm{CD}_{4}^{+}$and $\mathrm{CD} 8^{+} \mathrm{T}$ cells from AML patients, compared with those from HD. The mean frequency $( \pm \mathrm{SD})$ of Blimp $-1^{+}$cells among $\mathrm{CD} 4^{+} \mathrm{T}$ cells was $41.2 \pm 14.8 \%$ vs. $49.8 \pm 9.5 \%, \quad P=0.0196$ (Fig. 1a, b), while those of $\mathrm{CD}^{+} \mathrm{T}$ cells was $20.3 \pm$ $7.9 \%$ vs. $35.4 \pm 17.3 \%, P<0.0001$ (Fig. 1a, b). To determine the expression of Blimp-1 in protein level, we performed intracellular staining of Blimp-1 in both $\mathrm{CD}^{+}$and $\mathrm{CD}^{+} \mathrm{T}$ cells. Consistent with the mRNA data, the frequency of Blimp- $1^{+} \mathrm{T}$ cells was significantly higher in AML patients, compared with those in HD (Fig. 1c, d). This data indicates a potential role for Blimp-1 in AML.

\section{Elevated Blimp-1 expression on $\mathrm{CD}^{+} \mathrm{T}$ cells correlates with high circulating blasts in AML patients}

We next analyzed the correlation of Blimp-1 expression with the clinical characteristics in AML patients. Based on the level of Blimp-1 mRNA expression on $\mathrm{T}$ cells, we defined high-Blimp-1 (Blimp-1 $\geq 49.8 \%$ of $\mathrm{CD} 4^{+} \mathrm{T}$ cells, $\geq 35.4 \%$ of $\mathrm{CD} 8^{+} \mathrm{T}$ cells) vs. low-Blimp-1 (Blimp-1 $<49.8 \%$ of $\mathrm{CD}^{+} \mathrm{T}$ cells, $<35.4 \%$ of $\mathrm{CD}^{+} \mathrm{T}$ cells) subgroups in AML patients. The median values of Blimp-1 expression on $\mathrm{T}$ cells of the 24 AML patients evaluated in our study were used to establish the cutoff values. Patients with high Blimp-1 expression in $\mathrm{CD}^{+} \mathrm{T}$ cells had comparable clinical characteristics with that of low Blimp-1 expression (Additional file 1: Table S1). We further dissected the association of Blimp-1 

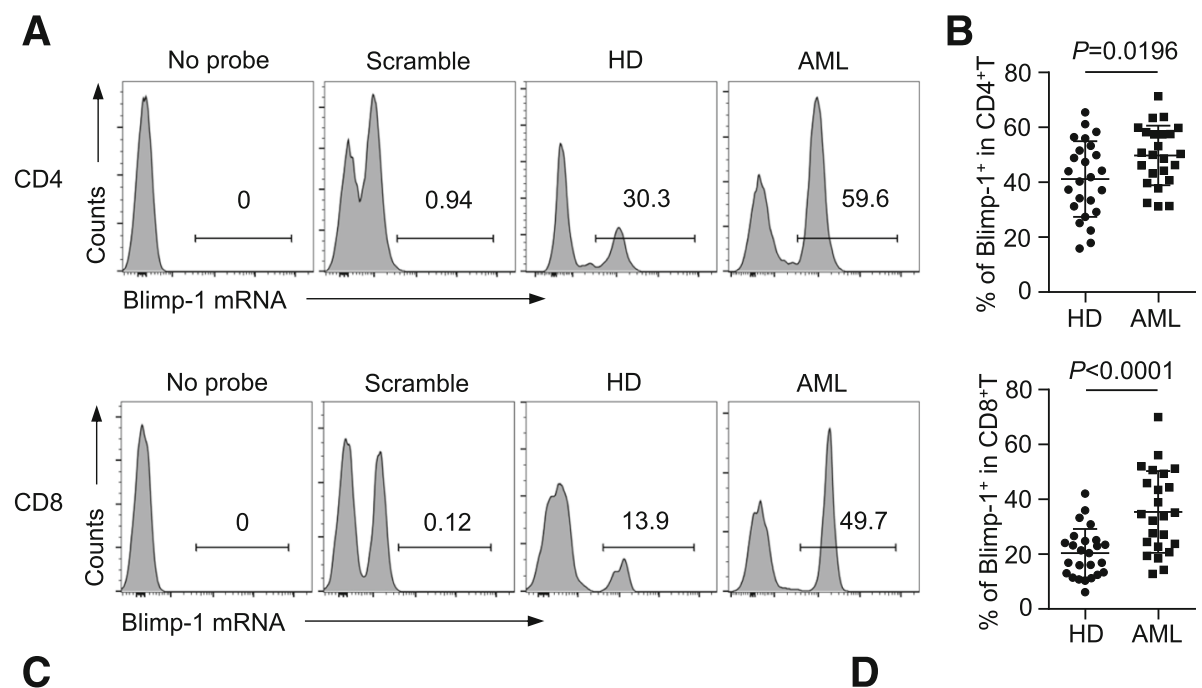

$\mathbf{C}$
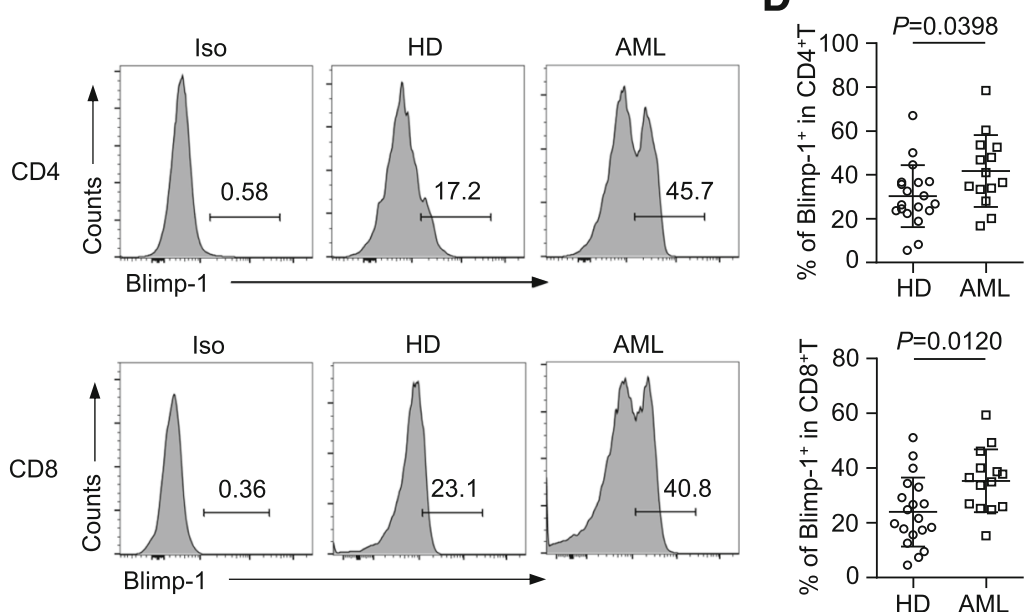

Fig. 1 Blimp-1 is elevated in T cells from AML patients. PBMCs collected from AML patients at initial diagnosis as well as healthy donors were assessed. $\mathbf{a}$, $\mathbf{b}$ Expression of Blimp-1 mRNA was assessed by SmartFlare probe followed by flow cytometry analysis. a Representative histograms displaying the expression of Blimp-1 mRNA gated on CD4 (left) and CD8 ${ }^{+}$T cells (right). Data from one healthy donor and one AML patient are shown. Scrambled SmartFlare probes were set as negative controls. $\mathbf{b}$ Plot of percentages of Blimp- $1^{+}$cells in $\mathrm{CD} 4^{+}$and $\mathrm{CD} 8^{+} \mathrm{T}$ cells from healthy donors ( $n=25)$ vs. AML patients $(n=24)$. c, d Expression of Blimp-1 protein was assessed by intracellular staining. $\mathbf{c}$ Representative flow cytometry data. $\mathbf{d}$ Plot of percentages of Blimp $-1^{+}$cells in CD4 ${ }^{+}$and $C D 8^{+}$T cells from healthy donors $(n=19)$ vs. AML patients $(n=14)$. Each spot represents an individual patient or healthy donor. $P$ values were obtained by unpaired $t$ test.

expression in $\mathrm{CD}^{+} \mathrm{T}$ cells to clinical characteristics (Table 1). We found no significant difference between the two groups (high Blimp-1 vs. low Blimp1 ) in terms of age, gender, and cytogenetic features. However, we observed that patients expressing a high frequency of Blimp-1 mRNA in $\mathrm{CD}^{+} \mathrm{T}$ cells presented with significantly higher white blood counts (WBC) at initial diagnosis. A high, yet comparable proportion of WBCs were leukemia blasts in both the high- and low-Blimp-1 groups. Therefore, the absolute blast counts in the peripheral blood were significantly higher in patients with high Blimp-1-expressing $\mathrm{CD}^{+} \mathrm{T}$ cells compared to that of patients with low Blimp-1 expression (Table 1).

\section{Expression of Blimp-1 correlates with the upregulation of} inhibitory receptors on T cells from AML patients

To examine whether there is an association between the expression of Blimp-1 and multiple inhibitory receptors in AML, PBMCs collected from AML patients were cocultured with Blimp-1 probe followed by co-staining with antibodies to inhibitory receptors including PD-1, TIGIT, 2B4, CD160, and TIM-3. Multi-channel flow cytometry analysis was performed to detect the expression of inhibitory receptors on $\mathrm{T}$ cells that co-express Blimp1 mRNA. As shown in Fig. 2a, Blimp- $1^{+} \mathrm{CD} 4^{+} \mathrm{T}$ cells expressed significantly higher levels of all inhibitory receptors tested than Blimp-1 $1^{-} \mathrm{CD} 4^{+} \mathrm{T}$ cells. $\mathrm{CD} 8^{+} \mathrm{T}$ cells demonstrated a similar expression pattern although only 
Table 1 High Blimp-1 expression on CD4 ${ }^{+} \mathrm{T}$ cells associates with increased blast in $\mathrm{AML}$

\begin{tabular}{|c|c|c|c|}
\hline $\begin{array}{l}\text { Total } \\
(n=24)\end{array}$ & $\begin{array}{l}\text { High-Blimp-1 } \\
(n=13)\end{array}$ & $\begin{array}{l}\text { Low-Blimp-1 } \\
(n=11)\end{array}$ & $P$ value \\
\hline \multicolumn{4}{|l|}{ Age, years } \\
\hline Median & 61 & 59 & 0.797 \\
\hline Range & $23-75$ & $24-77$ & \\
\hline \multicolumn{4}{|l|}{ Gender } \\
\hline Male & 6 & 4 & 0.628 \\
\hline Female & 7 & 7 & \\
\hline \multicolumn{4}{|l|}{$\mathrm{WBC}, \times 10^{9} / \mathrm{I}$} \\
\hline Median & 82.9 & 24.9 & 0.033 \\
\hline Range & $5.8-364.6$ & $5.1-87$ & \\
\hline \multicolumn{4}{|l|}{ PB blast, \% } \\
\hline Median & 68 & 73 & 0.721 \\
\hline Range & $1.9-93.8$ & 18-90.8 & \\
\hline \multicolumn{4}{|c|}{ Absolute blast counts, $\times 10^{9} / /$} \\
\hline Median & 41 & 16 & 0.026 \\
\hline Range & $0.1-342$ & $3-47$ & \\
\hline \multicolumn{4}{|l|}{ BM blast, \% } \\
\hline Median & 60 & 64.5 & 0.626 \\
\hline Range & $1.5-88$ & $34.5-79$ & \\
\hline \multicolumn{4}{|l|}{ Cytogenetics $^{a}$} \\
\hline Adverse & 6 & 6 & 0.799 \\
\hline Intermediate & 5 & 4 & \\
\hline Favorable & 1 & 1 & \\
\hline
\end{tabular}

WBC white blood cell, $A N C$ absolute neutrophil counts, $P B$ peripheral blood, $B M$ bone marrow, ITD internal tandem duplication.

${ }^{\text {a }}$ Risk stratification is based on the 2017 European Leukemia Net

Recommendations. Clinical information for risk stratification was not available for one patient, thus data of 23 (12 of high Blimp-1, 11 of low Blimp-1) are shown

TIGIT and PD-1 achieved statistical significance (Fig. 2b). Expression of Blimp-1 was positively correlated with the expression of PD-1 and TIGIT in both $\mathrm{CD} 4^{+}$and $\mathrm{CD} 8^{+}$ $\mathrm{T}$ cells from AML (Additional file 1: Figure S1). Thus, expression of Blimp-1 associates with the upregulation of multiple inhibitory receptors on $\mathrm{T}$ cells from AML patients, suggesting a potential effect of Blimp-1 in suppressing T cell function in AML.

\section{Expression of Blimp-1 in $\mathrm{CD}^{+}{ }^{+}$cells associates with increased differentiation of terminally differentiated effector T cells in AML}

We further performed phenotypic analyses to evaluate the differentiation status of $\mathrm{T}$ cells that express Blimp-1 mRNA in patients with AML. Based on the expression of CD45RA and CCR7, T cells can be divided into four subpopulations: naïve $\mathrm{T}$ cells $\left(\mathrm{T}_{\mathrm{N}}, \mathrm{CCR} 7^{+} \mathrm{CD} 45 \mathrm{RA} \mathrm{A}^{+}\right)$, central memory $\mathrm{T}$ cells $\left(\mathrm{T}_{\mathrm{CM}}, \mathrm{CCR} 7^{+} \mathrm{CD} 45 \mathrm{RA}^{-}\right)$, effector memory $\mathrm{T}$ cells ( $\mathrm{T}_{\mathrm{EM}}, \mathrm{CCR}^{-} \mathrm{CD}^{-} 45 \mathrm{RA}^{-}$), and terminally differentiated effector cells $\left(\mathrm{T}_{\text {EMRA }}, \mathrm{CCR} 7^{-} \mathrm{CD} 45 \mathrm{RA}^{+}\right.$) [36-39]. Consistent with a previous report that Blimp-1 is mainly expressed in $\mathrm{T}$ cells post antigen stimulation $[29,40]$, we observed that the majority of Blimp- $1^{+} \mathrm{T}$ cells are antigen-experienced cells in AML patients. Blimp $-1^{+}$cells among both $\mathrm{CD}^{+}$and $\mathrm{CD}^{+} \mathrm{T}$ cells showed significantly increased $\mathrm{T}_{\mathrm{CM}}$ and $\mathrm{T}_{\mathrm{EM}}$ compared to that of Blimp-1- $1^{-}$cells. In contrast, Blimp-1- $1^{-}$cells were mostly naive (Fig. 3). Importantly, the frequency of $\mathrm{T}_{\mathrm{EMRA}}$ was significantly higher in Blimp $-1^{+} \mathrm{CD} 8^{+} \mathrm{T}$ cells (Fig. 3). $T_{\text {EMRA }}$ are considered as terminal effector cells with limited functional capacity; thus, these data provide further support that Blimp-1 negatively influences $\mathrm{T}$ cell response in AML.

\section{Blimp- $1^{+} \mathrm{T}$ cells from AML patients display functional defects manifested by reduced cytokine production and cytotoxic capacity}

To evaluate the functional status of Blimp $-1^{+} \mathrm{T}$ cells from the AML patients, we tested cytokine release upon in vitro stimulation with anti-CD3 and antiCD28. Intracellular production of IFN- $\gamma$ and IL-2 were assessed by flow cytometry analysis gated on Blimp- $1^{+}$vs. Blimp- $1^{-} \mathrm{T}$ cells. Of note, we were not able to examine the mRNA expression of Blimp-1 in this experiment as the RNA probe leaks postpermeabilization during intracellular staining for cytokines. Therefore, Blimp- $1^{+} \mathrm{T}$ cells were defined by intracellular staining of Blimp-1 protein (Fig. 4a). As shown in Fig. 4b, the Blimp- $1^{+}$subpopulation of both $\mathrm{CD}^{+}$and $\mathrm{CD}^{+} \mathrm{T}$ cells had significantly lower intracellular IFN- $\gamma$ compared to Blimp-1 ${ }^{-}$T cells. Blimp-1 ${ }^{+} \mathrm{CD}_{4}^{+} \mathrm{T}$ cells also displayed less IL-2 production compared to that of Blimp- $1^{-} \mathrm{CD} 4^{+} \mathrm{T}$ cells. We next assessed the cytotoxic potential by examining the level of perforin expression in each $\mathrm{T}$ cell subpopulation. Without in vitro stimulation, $\mathrm{CD}^{+} \mathrm{T}$ cells appear to express less Blimp-1 (Fig. 4c). Importantly, we observed a significant lower expression of perforin and Granzyme B in Blimp $-1^{+} \mathrm{CD} 8^{+} \mathrm{T}$ cells, compared to that in Blimp- $1^{-} \mathrm{CD}^{+} \mathrm{T}$ cells (Fig. 4d, Additional file 1: Figure S2A). Collectively, these results demonstrate that Blimp $-1^{+} \mathrm{T}$ cells have a decreased function compared to Blimp-1 $1^{-} \mathrm{T}$ cells in AML patients.

\section{Inhibition of Blimp-1 improves T cell function}

To further dissect the regulatory effect of Blimp-1 on $\mathrm{T}$ cell function, we used a specific siRNA to knockdown Blimp-1 expression in T cells from the AML patients. The expression of Blimp-1 was reduced by $60 \%$ in both $\mathrm{CD}^{+}$ and $\mathrm{CD} 8^{+} \mathrm{T}$ cells after transfection with Blimp-1 siRNAs (Fig. 5a). Intracellular cytokine staining assays were performed on $\mathrm{T}$ cells upon in vitro stimulation with anti-CD3 

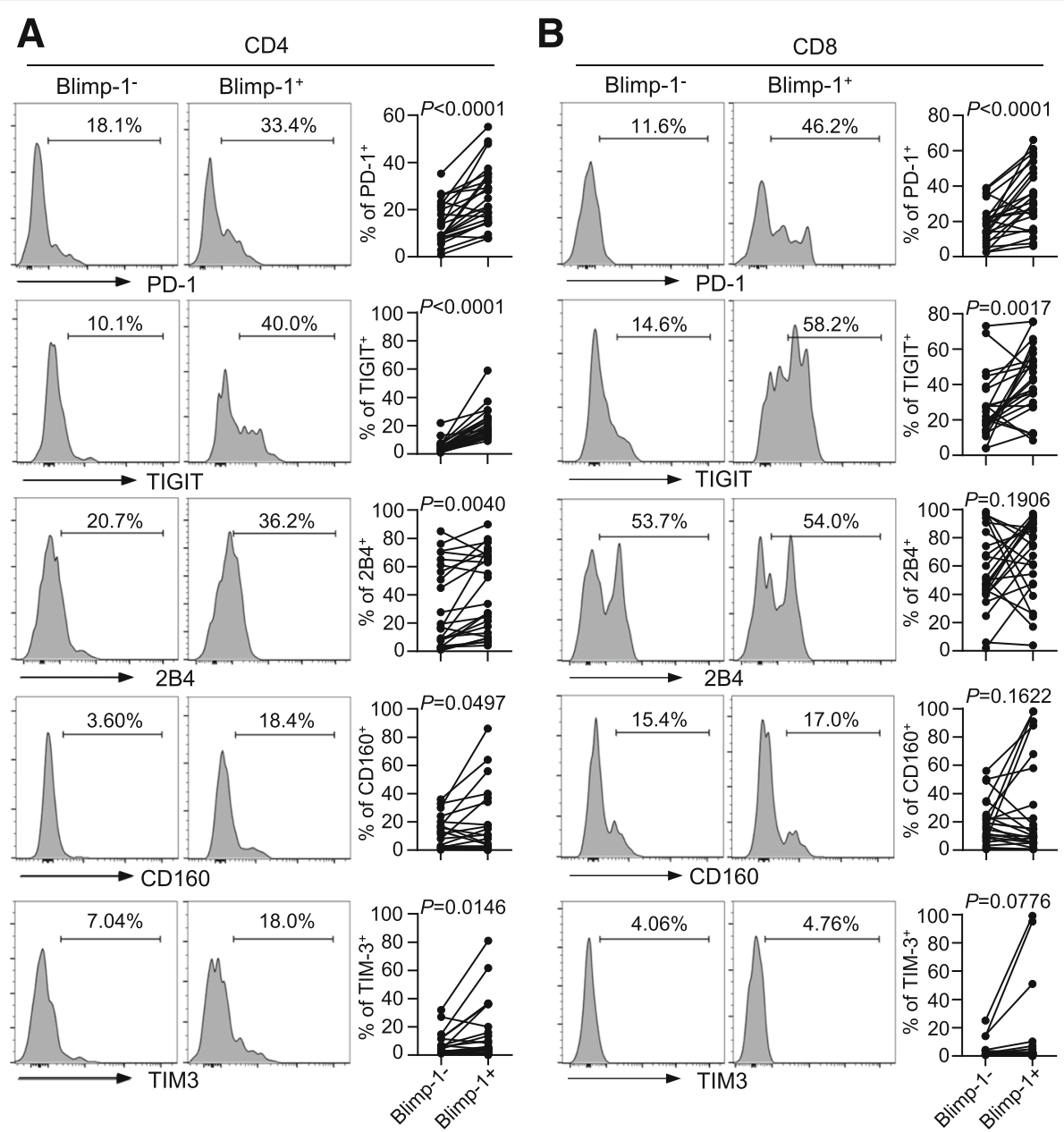

Fig. 2 Expression of Blimp-1 correlates with the upregulation of inhibitory receptors on T cells from AML patients. Flow cytometry analysis of expression of PD-1, TIGIT, 2B4, CD160, and TIM-3 on Blimp- $1^{-}$vs. Blimp- $1^{+}$T cells from AML patients $(n=24)$. Blimp-1 mRNA expression are detected by SmartFlare. Data of $\mathrm{CD}^{+}(\mathbf{a})$ and $\mathrm{CD}^{+}$(b) T cells are shown. Panels on the right of each set of representative histograms are plots of expression of each receptor on Blimp-1 $1^{-}$vs. Blimp- $1^{+} T$ cells. $P$ values were obtained by paired $t$ test and Wilcoxon signed-rank test.

and anti-CD28. We observed a significant increase of IFN- $\gamma$ and IL-2 production after Blimp-1 inhibition by siRNA; this occurred in both $\mathrm{CD}^{+}$and $\mathrm{CD}^{+} \mathrm{T}$ cells (Fig. 5b). Consistently, CD8 ${ }^{+} \mathrm{T}$ cells expressed increased levels of perforin and Granzyme B upon Blimp-1 knockdown, indicating an improved cytotoxic capacity (Fig. 5c, Additional file 1: Figure S2B). Of note, Blimp-1 did not appear to regulate apoptosis as we observed no change of CD95 expression on $\mathrm{T}$ cells upon Blimp-1 knockdown (Additional file 1: Figure S3). These important data demonstrate a pivotal role for Blimp-1 in inhibiting cytokine release and cytotoxic capacity, thus suppressing $\mathrm{T}$ cell function in AML patients.

\section{Blimp-1 is a direct transcriptional regulator of PD-1 and TIGIT}

Our study demonstrated a tight correlation of Blimp1 expression to that of PD-1 and TIGIT in AML
(Fig. 2), we hypothesize that Blimp-1 suppresses T cell function by regulating the expression of these two inhibitory receptors. There are two isoforms of Blimp-1 detected in the T cells from AML: isoforms 1 and 2, which were encoded by transcript variant positive regulatory domain containing 1 alpha $(P R D M 1 \alpha)$ and $P R D M 1 \beta$, respectively (Additional file 1: Figure S4). Blimp-1 isoform 2 has a truncated PR domain, lacking the N-terminal 101 amino acids of isoform 1 . We performed a luciferase assay using PD-1 and TIGIT luciferase reporters. Both PRDM1 $\alpha$ and $P R D M 1 \beta$ exert a significant transcriptional activity for the expression of PD-1 and TIGIT. PRDM1 $\beta$ appears to be more dominant (Fig. 6a). To test whether there is a direct binding of Blimp-1 to the promoter of $P D-1$ and TIGIT, we analyzed the promoter sequences of $P D-1$ and TIGIT. One and two binding sites for Blimp-1 were located on the promoter of PD-1 and 

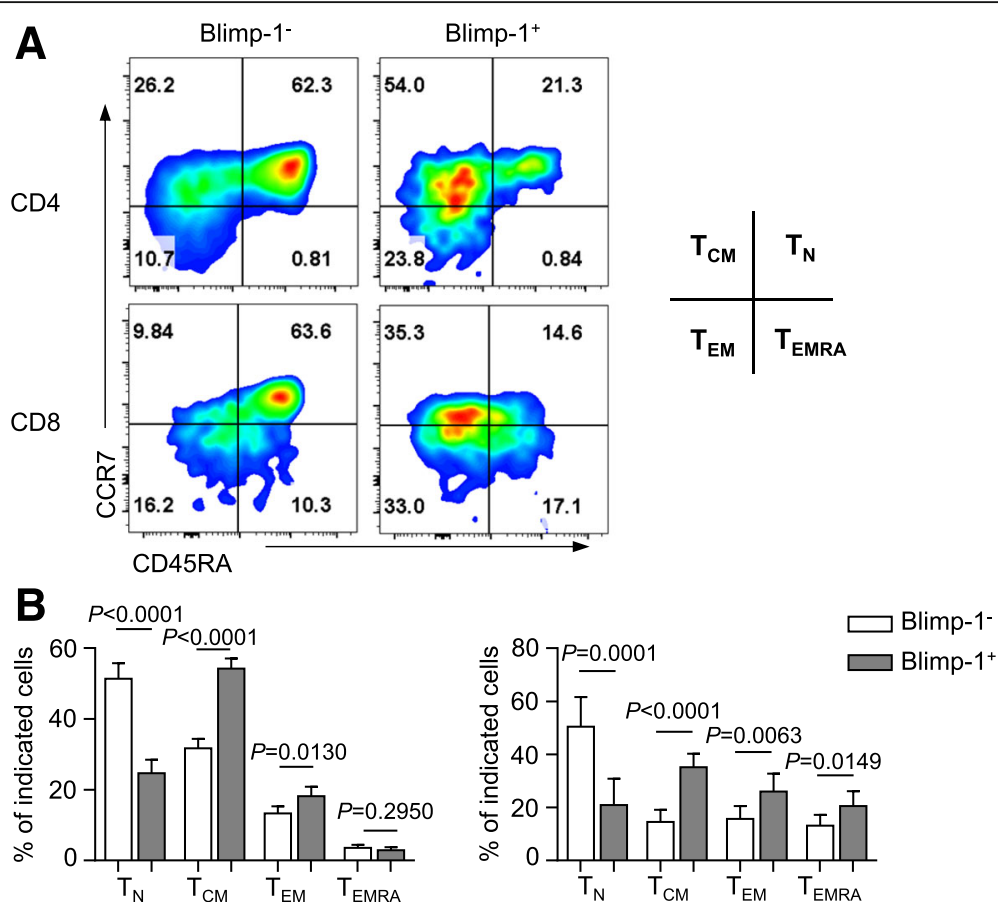

Fig. 3 Expression of Blimp-1 in CD8 ${ }^{+}$T cells associates with increased differentiation of terminal differentiated effector T cells in AML. Distribution of $T_{N}, T_{C M}, T_{E M}$, and $T_{E M R A}$ within Blimp- $1^{-}$vs. Blimp- $1^{+} T$ cells from AML patients $(n=14)$ are assessed by flow cytometry. Both CD4 ${ }^{+}$and $C D 8^{+} T$ cells are evaluated. Representative flow data (a) and plots (b) of percentage of each T cell differentiation subset among Blimp- $1^{-}$vs. Blimp- $1^{+} \mathrm{T}$ cells are shown. $P$ values were obtained by paired $t$ test and Wilcoxon signed-rank test.

TIGIT, respectively (Fig. 6b). In a ChIP assay using $\mathrm{T}$ cells purified from PBMCs of a healthy donor, we observed a clear interaction between Blimp-1 and its binding site on the $P D-1$ promoter. Between the two putative binding sites on the TIGIT promoter, Blimp1 binds to site A, but not site B (Fig. 6c). Thus, there is a direct binding of Blimp-1 to the promoters of PD-1 and TIGIT.

To determine whether Blimp-1 regulates the expression of PD-1 and TIGIT in AML, we first assessed the effect of Blimp-1 knockdown on the mRNA expression of PD-1 and TIGIT using T cells purified from PBMCs of AML patients. Consistent with our findings in Fig. 5a, Blimp-1 knockdown efficiently silenced its mRNA (Fig. 7a). Importantly, we observed a significant decrease of PD- 1 and TIGIT mRNA in both $\mathrm{CD}^{+}$and $\mathrm{CD} 8^{+} \mathrm{T}$ cells upon Blimp-1 knockdown. As a control, BCL-6 mRNA was increased upon Blimp-1 knockdown (Fig. 7a). We next performed a study overexpressing the transcripts PRDM1 $\alpha$ and PRDM1 $\beta$ in a human $\mathrm{T}$ cell line MT4 cell. We observed a significant elevation of both PD- 1 and TIGIT mRNA. In contrast, BCL- 6 mRNA was decreased when PRDM1 $\alpha$ or PRDM1 $\beta$ was overexpressed (Fig. 7b).

Taken together, these data demonstrate that the transcription factor Blimp-1 can bind to the promoters of
PD-1 and TIGIT and positively regulate the expression of these two inhibitory receptors.

\section{Discussion}

Blimp-1, encoded by the PRDM1 gene, was initially identified as a transcriptional repressor regulating terminal differentiation of B cells into plasma cells [41]. The effect of Blimp-1 in lymphoproliferative disorders has been well studied [42-47]. Recent studies using mouse models of virus infection elucidated its role in $\mathrm{T}$ cell differentiation. During acute viral infections, Blimp-1 promotes the differentiation of $\mathrm{CD}^{+} \mathrm{T}$ cells into short-lived terminal effectors while dampening the formation of long-lived central memory $\mathrm{T}$ cells [40, 48-50]. During chronic viral infection, Blimp-1 enhances expression of inhibitory receptors and promotes development of $\mathrm{T}$ cell exhaustion [29, 51, 52]. Notably, haploinsufficient mice which had intermediate expression of Blimp-1 controlled chronic virus infection better than either wild type or Blimp-1fully deficient mice, indicating that a moderate amount of Blimp-1 facilitates effector mechanisms without causing $\mathrm{T}$ cell exhaustion $[29,30]$. These findings suggest a complex role for Blimp-1 in regulating $\mathrm{T}$ cell response. Although well studied in viral infection, the $\mathrm{T}$ cell regulatory role of Blimp-1 in tumor immunity 

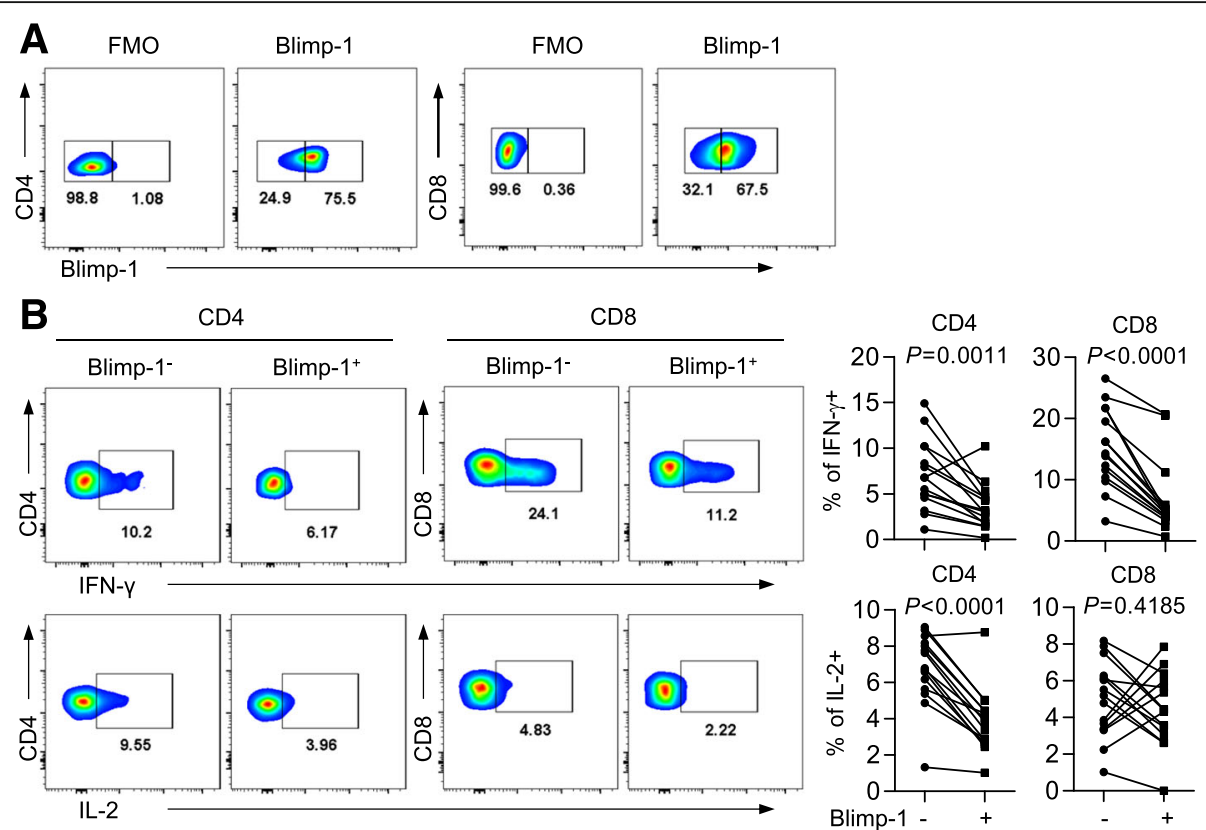

Blimp-1 - + +
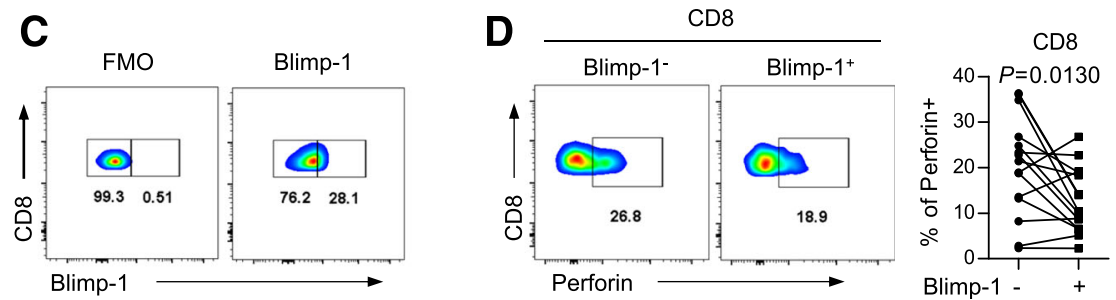

Fig. 4 Blimp $-1^{+} T$ cells from AML patients display functional defects by showing less cytokine production and capacity of cytotoxicity. $\mathbf{a}$, b PBMCs collected from AML patients were stimulated in vitro with anti-CD3 and anti-CD28 before intracellular staining with Blimp-1, IFN- $\gamma$, and IL-2. a Flow cytometry data showing Blimp-1 expression in both $C D 4^{+}$and $C D 8^{+} T$ cells. Fluorescence-minus-one (FMO) stains were used as negative controls. $\mathbf{b}$ Intracellular production of IFN- $\gamma$ and IL-2 among Blimp- $1^{-}$vs. Blimp $-1^{+}$T cells from AML patients $(n=15)$ were dissected. Shown are representative dot plots (left) and a plot of frequency (right) for IFN- $\gamma$ and IL-2, respectively. Data of both $\mathrm{CD} 4^{+}$and $\mathrm{CD} 8^{+} \mathrm{T}$ cells are shown. $\mathbf{c}$ Flow cytometry data showing Blimp-1 expression in $\mathrm{CD} 8^{+} \mathrm{T}$ cells without in vitro stimulation. $\mathbf{d}$ Intracellular stain of perforin by Blimp- $1^{+} \mathrm{CD} 8^{+}$vs. Blimp- $1^{-} \mathrm{CD}^{+} \mathrm{T}$ cells from AML patients $(n=15)$. Representative flow data (left) and plot of the percentage of perforin ${ }^{+} \mathrm{CD}^{+} \mathrm{T}$ cells (right) are shown. $P$ values were obtained by paired $t$ test.

has not been fully defined and the effect of Blimp-1 on anti-leukemia response is unknown. In this study, phenotypic and functional analyses of PBMCs collected from AML patients were performed. We focused on dissecting the role of Blimp-1 in modulating the $\mathrm{T}$ cell response in AML. Our study demonstrates that expression of Blimp-1 in both $\mathrm{CD}^{+}$and $\mathrm{CD} 8^{+} \mathrm{T}$ cells is significantly increased in AML patients compared to that in healthy donors. Consistent with exhaustion, Blimp $-1^{+} \mathrm{T}$ cells express high levels of coinhibitory receptors such as PD-1 and TIGIT. In addition, they are phenotypically skewed toward terminal effector differentiation and functionally impaired in their production of cytokines and potential for cytotoxicity. Importantly, the functional defect is reversed by inhibition of Blimp-1 via siRNA knockdown. To our knowledge, this study is the first to display an immune suppressive role of Blimp-1 in AML. Our finding suggests that Blimp-1 associates with $\mathrm{T}$ cell exhaustion and suppresses $\mathrm{T}$ cell function, which may subsequently impair anti-leukemia immune response. Therefore, targeting Blimp-1 may provide effective therapeutics for AML.

We observed a wide variation of Blimp-1 expression in $\mathrm{T}$ cells among AML patients. Clinically, the initial presentation of AML is highly heterogeneous [53]. Some patients seek medical attention earlier during the disease course due to their high sensitivity to leukemia-related symptoms or occasionally incidental abnormal laboratory findings; others present later when the leukemia has developed for a longer period of time. The large variation of Blimp-1 expression among the AML patients may represent their different disease status. In fact, we found a significant 

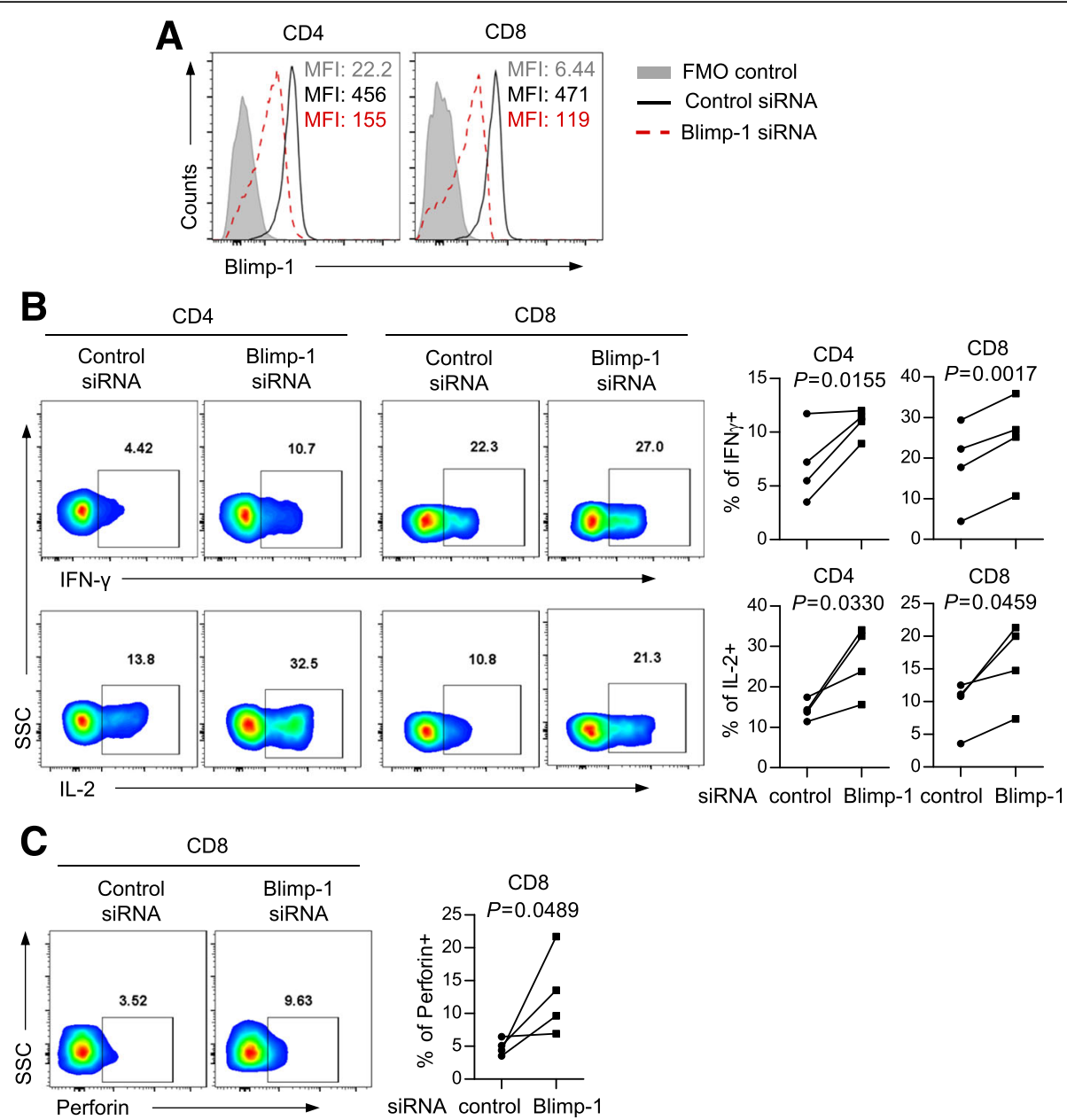

Fig. 5 Blimp-1 knockdown with siRNA increases cytokine production and cytotoxicity capacity in T cells from AML patients. a Histograms of Blimp-1 MFI show the efficiency of Blimp-1 siRNA knockdown. $\mathbf{b}$ Intracellular cytokine production by purified $C D 4^{+}$and $C D 8^{+} T$ cells from $A M L$ patients $(n=4)$ upon anti-CD3/anti-CD28 stimulation. $\mathbf{c}$ Intracellular production of perforin by purified CD $8^{+} \mathrm{T}$ cells from AML patients $(n=4)$ upon Blimp-1 knockdown. Shown are representative flow data (left) and plot of frequency (right). $P$ values were obtained by paired $t$ test.

association of Blimp-1 expression with the number of circulating leukemia blast. Patients who express high levels of Blimp-1 in their $\mathrm{CD}_{4}^{+} \mathrm{T}$ cells present with high blast counts, indicating a correlation of Blimp-1 expression to late phase leukemia development. This situation might provide persistent leukemia antigen that is ideal for induction of $\mathrm{T}$ cell exhaustion, which is consistent with our finding that Blimp- $1^{+} \mathrm{T}$ cells associate with exhaustion and display functional impairment. Thus, we speculate that treatment approaches targeting $\mathrm{T}$ cell exhaustion may be more effective in patients with higher expression of Blimp-1 as $\mathrm{T}$ cells in this patient population are more likely exhausted. Therefore, testing Blimp-1 expression in $\mathrm{T}$ cells might provide a crucial biomarker for effective leukemia treatment. Although promising, further studies of large size of samples are needed to make a definitive conclusion.
The mechanisms by which Blimp-1 regulates $\mathrm{T}$ cell responses are not fully understood. In our study, we observed a strong correlation between Blimp-1 expression and upregulation of inhibitory receptors such as PD-1 and TIGIT. Several studies have demonstrated an important role of PD-1 in inhibiting anti-leukemia $\mathrm{T}$ cell responses $[20,21,24]$. In addition, our recent study revealed that TIGIT contributes to T cell impairment in AML and associates with poor clinical outcomes [26]. We hypothesize that in AML, Blimp-1 suppresses T cell function through positive regulation of these inhibitory pathways. In the present study, we demonstrated a strong binding of Blimp-1 protein to the promoters of the genes encoding PD-1 and TIGIT. Importantly, inhibition of Blimp-1 by siRNA knockdown significantly decreased mRNA expression of PD-1 and TIGIT in T cells collected from AML patients. Consistently, cells overexpressing Blimp-1 showed upregulation of PD-1 and TIGIT. Therefore, 


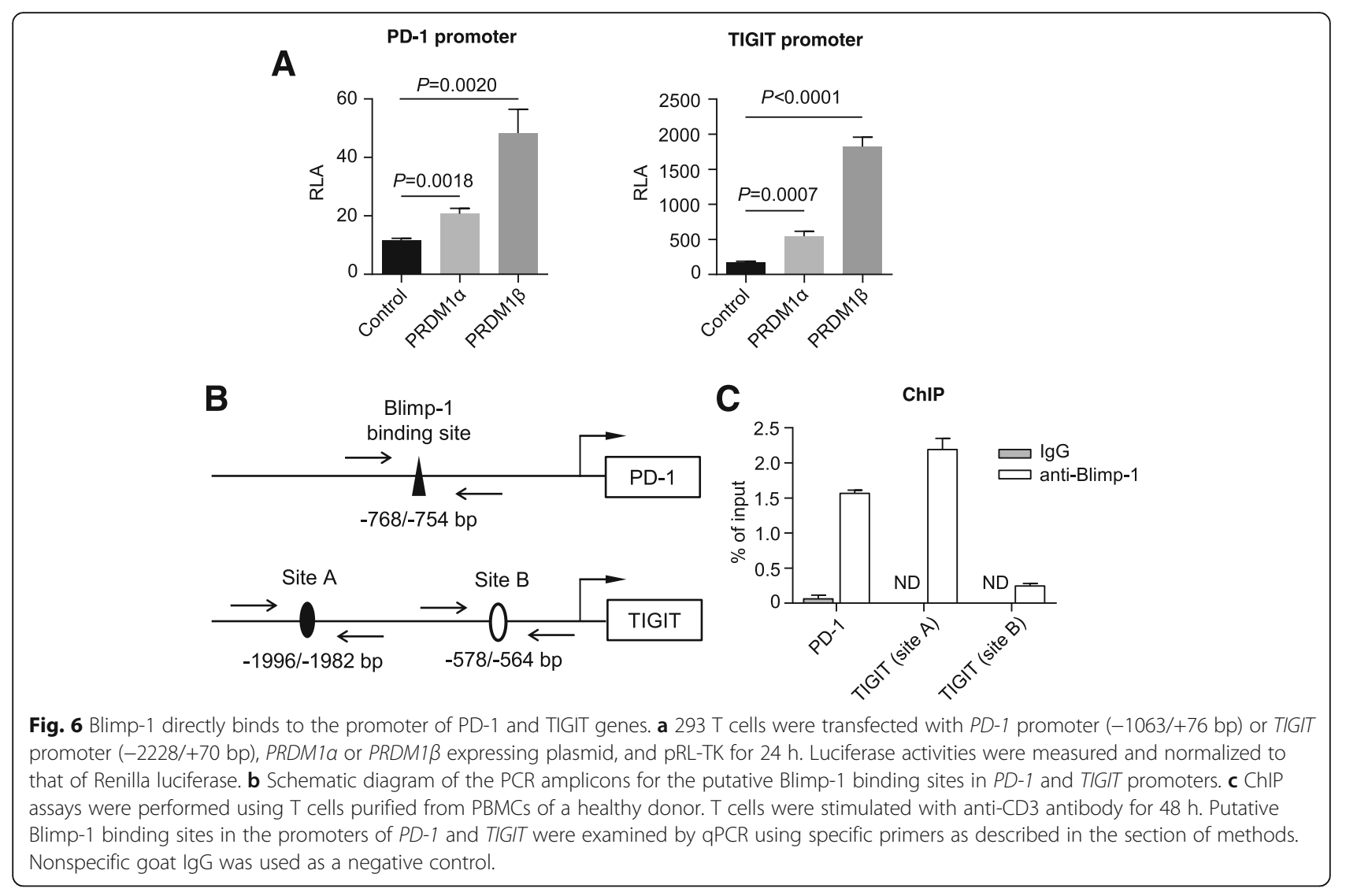

Blimp-1 is a transcriptional regulator for these two important inhibitory receptors. This likely contributes to the mechanisms by which Blimp-1 suppresses $\mathrm{T}$ cell function in AML. An equally important question is how and why Blimp-1 is upregulated in AML. In viral infection, Blimp-1 expression is induced during $\mathrm{T}$ cell activation upon viral antigen stimulation [31]. Cytokines including IL-2 have been reported to be crucial mediators for the upregulation of Blimp-1. In AML, it has been observed that serum level of IL-2 is increased in AML patients, and the level is particularly higher in patients with high WBC at initial presentation [54]. Consistently, we observed a positive correlation between the high level of WBC and Blimp-1 expression in our study. We speculate that IL-2 and/or other cytokines may contribute to the regulation of Blimp-1 in AML. Further studies are warranted to address this important question.

In contrast to our finding that Blimp-1 upregulates the expression of PD-1, Lu et al. have reported that Blimp-1 inhibits $\mathrm{CD}^{+} \mathrm{T}$ cell expression of PD-1[55]. Of note, their conclusion was drawn from a study of acute viral infection, in which PD-1 was increased shortly (hours) after antigen stimulation. The regulation mechanisms may be significantly different in the setting of chronic infections or cancer. Consistent with our finding, it has been reported that $\mathrm{PD}-1^{+} \mathrm{T}$ cells expressed a high level of Blimp-1 in patients with chronic lymphocytic leukemia [56]. In addition, studies using mouse models of viral infection have demonstrated that Blimp-1 enhanced the expression of inhibitory receptors on exhausted $\mathrm{T}$ cells during chronic viral infection and conditional deletion of Blimp-1 reversed this process [29]. Collectively, these observations highlight the importance of the context (disease status)-specific transcriptional mechanisms during $\mathrm{T}$ cell differentiation.

Majority of studies demonstrate a dominant role of $\mathrm{CD}^{+} \mathrm{T}$ cells in host defense. Features of $\mathrm{CD} 8^{+} \mathrm{T}$ cell exhaustion and its effect on dysfunctional immune status have been extensively investigated [57]. Recent observations of $\mathrm{CD}^{+} \mathrm{T}$ cell exhaustion in chronic viral infections suggest that $\mathrm{CD}^{+} \mathrm{T}$ cells are also crucial for optimal infection control [58, 59]. Most recently, Hwang et al. reported that Blimp-1 is upregulated and acts as a critical regulator for $\mathrm{CD} 4^{+}$ $\mathrm{T}$ cell exhaustion during chronic toxoplasmosis. Conditional deletion of Blimp-1 in $\mathrm{CD} 4^{+} \mathrm{T}$ cells regained $\mathrm{CD}^{+} \mathrm{T}$ cell function and improved infection control [60]. Contributions of $\mathrm{CD} 4^{+} \mathrm{T}$ cell in leukemia are not well defined. Our findings demonstrate that, in 


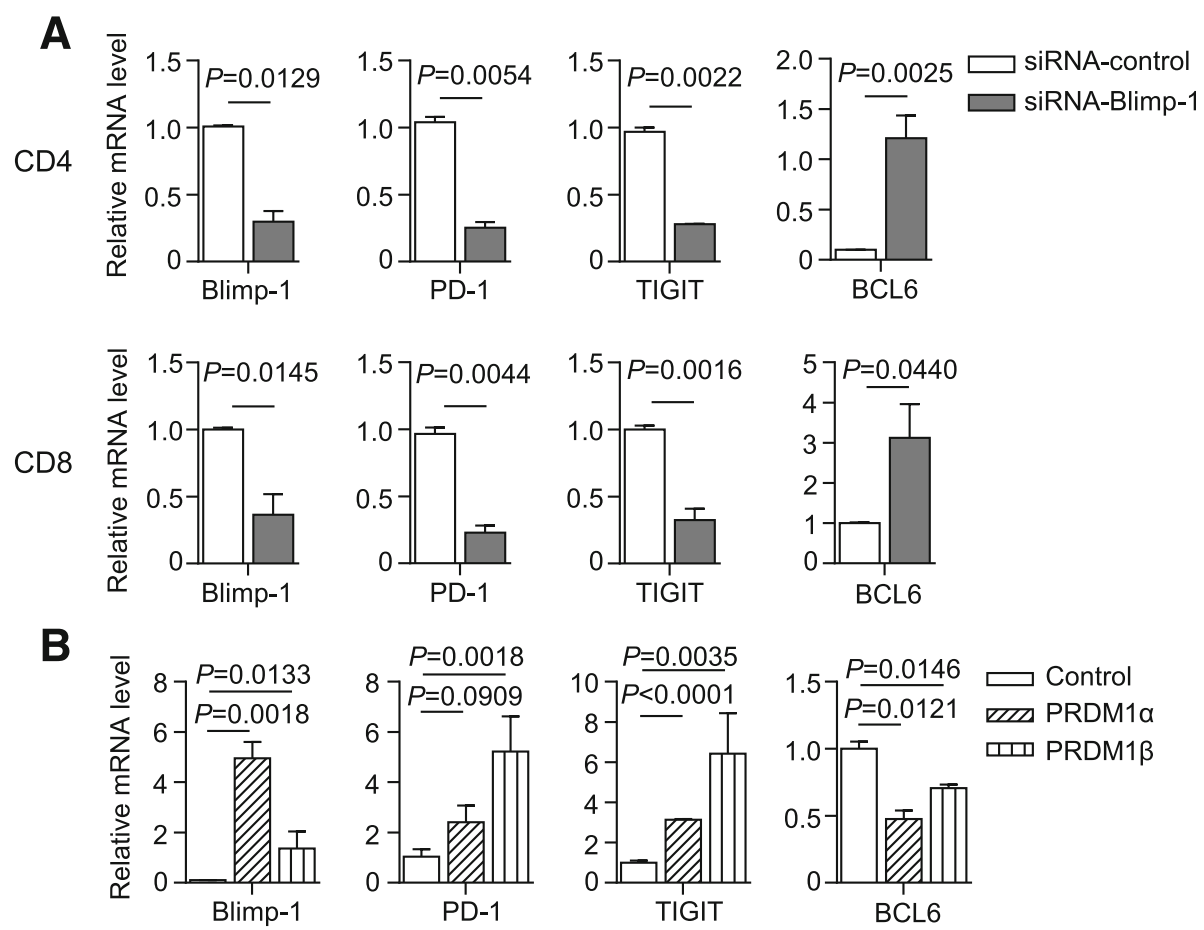

Fig. 7 Blimp-1 positively regulates the expression of PD- 1 and TIGIT. a Purified CD4 ${ }^{+}$and CD $8^{+}$T cells from AML patients $(n=3)$ were transfected with indicated siRNA. Expression of mRNA for Blimp-1, PD-1, TIGIT, and BCL-6 upon Blimp-1 knockdown was assessed by real-time PCR. b MT4 cells were transfected with PRDM1a and PRDM1 $\beta$ plasmids for $48 \mathrm{~h}$. The mRNA levels of Blimp-1, PD-1, TIGIT, and BCL6 were quantified by real-time PCR. Values were normalized to those of GAPDH and expressed relative to negative control. $P$ values were obtained by unpaired $t$ test.

addition to causing $\mathrm{CD}^{+} \mathrm{T}$ cell dysfunction, Blimp-1 plays an equally important role in mediating $\mathrm{CD}^{+}{ }^{+} \mathrm{T}$ cell suppression in AML. Blimp-1 upregulates coinhibitory receptors and associates with functional defect in both $\mathrm{CD} 4^{+}$and $\mathrm{CD} 8^{+} \mathrm{T}$ cells. Interestingly, high Blimp-1 expression in $\mathrm{CD}^{+}$, not $\mathrm{CD} 8^{+} \mathrm{T}$ cells, correlates with high circulating leukemia blast (Table 1), suggesting a potential unique contribution of $\mathrm{CD}^{+} \mathrm{T}$ cell dysfunction in AML pathogenesis.

\section{Conclusions}

Taken together, we demonstrate an inhibitory effect of Blimp-1 on T cell response in AML patients. Blimp-1 can do so by transcriptionally upregulating inhibitory receptors including PD-1 and TIGIT. A clinical correlative study showed an association between the elevated Blimp-1 expression and high circulating blasts in AML patients. Our findings have significant clinical impact as Blimp-1 may be a useful biomarker and an important target for effective novel leukemic therapeutics.

\section{Additional file}

Additional file 1: Figure S1. Expression of Blimp-1 positively correlates with TIGIT and PD-1 expression in AML. Figure S2: Blimp-1+ T cells express less Granzyme B, which is partially reversed by Blimp-1 knockdown. Figure
S3. The expression of CD95 was not affected by Blimp-1 knockdown. Table S1. Blimp-1 is expressed as two transcript variants PRDM1 1 and PRDM1 $\beta$ in $T$ cells from AML patients (PDF $451 \mathrm{~kb}$ )

\section{Abbreviations}

AML: Acute myeloid leukemia; Blimp-1: B lymphocyte-induced maturation protein 1; LAG-3: Lymphocyte-activation gene 3; PD-1: Programmed cell death protein 1; PRDM1a: Positive regulatory domain containing 1 alpha; TIGIT: T cell immunoglobulin and ITIM domain; TIM-3: T cell immunoglobulin domain and mucin domain 3; WBC: White blood counts

\section{Acknowledgements}

We thank all our patients for their trust, understanding, and willingness to provide their blood samples for our research.

\section{Funding}

This work was supported by the American Cancer Society Institutional Research Grant ACS IRG 124171-IRG-13-043-02 and the Kiesendahl Endowment funding (H Zheng). L.Z. is supported by the National Natural Science Foundation of China (No. 81671940).

\section{Availability of data and materials}

The datasets used and/or analyzed during the current study are available from the corresponding authors on reasonable request.

\section{Authors' contributions}

LZ designed the experiments, performed the experiments, analyzed the results, made the figures, and wrote the manuscript. YK and BJ designed the experiments, performed the experiments, and analyzed the results. DFC, WCE, WBR, NDP, and MB acquired the samples and managed the patients. MW provided the biostatistics support. JZ helped with the sample collection. TDS and RJH reviewed the manuscript. HZ designed the experiments, analyzed the results, and wrote the manuscript. $\mathrm{HZ}$ conceived the concept, 
designed the experiments, oversaw the interpretation and presentation of the data, and wrote the manuscript. All authors read and approved the final manuscript.

\section{Competing interests}

The authors declare that they have no competing interests.

\section{Consent for publication}

Not applicable.

\section{Ethics approval and consent to participate}

The study was approved by the Institutional Review Board of Penn State University College of Medicine. Full informed consent was obtained from all patients.

\section{Publisher's Note}

Springer Nature remains neutral with regard to jurisdictional claims in published maps and institutional affiliations.

\section{Author details}

${ }^{1}$ Institute of Infectious Diseases, Beijing Ditan Hospital, Beijing Key Laboratory of Emerging Infectious Diseases, Capital Medical University, Beijing, China. ${ }^{2}$ Penn State Cancer Institute, Penn State University College of Medicine, Hershey, PA, USA. ${ }^{3}$ Depatment of Medical Oncology, Thomas Jefferson

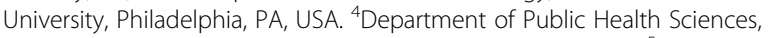
Penn State University College of Medicine, Hershey, PA, USA. ${ }^{5}$ Department of Pathology, Penn State Hershey Medical Center, Penn State University College of Medicine, Hershey, PA 17033, United States. ${ }^{6}$ Department of Microbiology and Immunology, Penn State University College of Medicine, Hershey, PA USA.

Received: 4 April 2017 Accepted: 2 June 2017

\section{Published online: 19 June 2017}

\section{References}

1. Schreiber RD, Old LJ, Smyth MJ. Cancer immunoediting: integrating immunity's roles in cancer suppression and promotion. Science. 2011;331(6024):1565-70.

2. Chen L, Han X. Anti-PD-1/PD-L1 therapy of human cancer: past, present, and future. J Clin Invest. 2015;125(9):3384-91.

3. Topalian SL, Drake CG, Pardoll DM. Immune checkpoint blockade: a common denominator approach to cancer therapy. Cancer Cell. 2015;27(4):450-61.

4. Callahan MK, Postow MA, Wolchok JD. Targeting T cell co-receptors for cancer therapy. Immunity. 2016;44(5):1069-78.

5. Wang J, Yuan R, Song W, Sun J, Liu D, Li Z. PD-1, PD-L1 (B7-H1) and tumor-site immune modulation therapy: the historical perspective. J Hematol Oncol. 2017:10(1):34.

6. Wherry EJ. T cell exhaustion. Nat Immunol. 2011;12(6):492-9.

7. Barber DL, Wherry EJ, Masopust D, Zhu B, Allison JP, Sharpe AH, Freeman GJ, Ahmed R. Restoring function in exhausted CD8 T cells during chronic viral infection. Nature. 2006;439(7077):682-7.

8. Jin HT, Anderson AC, Tan WG, West EE, Ha SJ, Araki K, Freeman GJ, Kuchroo VK, Ahmed R. Cooperation of Tim-3 and PD-1 in CD8 T-cell exhaustion during chronic viral infection. Proc Natl Acad Sci U S A. 2010;107(33):14733-8.

9. Ma W, Gilligan BM, Yuan J, Li T. Current status and perspectives in translational biomarker research for PD-1/PD-L1 immune checkpoint blockade therapy. J Hematol Oncol. 2016;9(1):47.

10. Blackburn SD, Shin H, Haining WN, Zou T, Workman CJ, Polley A, Betts MR, Freeman GJ, Vignali DA, Wherry EJ. Coregulation of CD8+ T cell exhaustion by multiple inhibitory receptors during chronic viral infection. Nat Immunol. 2009;10(1):29-37.

11. Diggs LP, Hsueh EC. Utility of PD-L1 immunohistochemistry assays for predicting PD-1/PD-L1 inhibitor response. Biomark Res. 2017;5:12.

12. Sakuishi K, Apetoh L, Sullivan JM, Blazar BR, Kuchroo VK, Anderson AC. Targeting Tim-3 and PD-1 pathways to reverse T cell exhaustion and restore anti-tumor immunity. J Exp Med. 2010;207(10):2187-94.

13. Johnston RJ, Comps-Agrar L, Hackney J, Yu X, Huseni M, Yang Y, Park S, Javinal $V$, Chiu $H$, Irving $B$, et al. The immunoreceptor TIGIT regulates antitumor and antiviral CD8(+) T cell effector function. Cancer Cell. 2014;26(6):923-37.
14. Chauvin JM, Pagliano O, Fourcade J, Sun Z, Wang H, Sander C, Kirkwood JM, Chen TH, Maurer M, Korman AJ, et al. TIGIT and PD-1 impair tumor antigenspecific CD8(+) T cells in melanoma patients. J Clin Invest. 2015;125(5):2046-58.

15. Koyama S, Akbay EA, Li YY, Herter-Sprie GS, Buczkowski KA, Richards WG, Gandhi L, Redig AJ, Rodig SJ, Asahina H, et al. Adaptive resistance to therapeutic PD-1 blockade is associated with upregulation of alternative immune checkpoints. Nat Commun. 2016;7:10501.

16. Schalper KA, Velcheti V, Carvajal D, Wimberly H, Brown J, Pusztai L, Rimm DL. In situ tumor PD-L1 mRNA expression is associated with increased TILs and better outcome in breast carcinomas. Clin Cancer Res. 2014;20(10):2773-82.

17. Fourcade J, Sun Z, Pagliano O, Chauvin JM, Sander C, Janjic B, Tarhini AA, Tawbi HA, Kirkwood JM, Moschos S, et al. PD-1 and Tim-3 regulate the expansion of tumor antigen-specific CD8(+) T cells induced by melanoma vaccines. Cancer Res. 2014;74(4):1045-55.

18. Zarour HM. Reversing T-cell dysfunction and exhaustion in cancer. Clin Cancer Res. 2016;22(8):1856-64.

19. Zhang L, Gajewski TF, Kline J. PD-1/PD-L1 interactions inhibit antitumor immune responses in a murine acute myeloid leukemia model. Blood. 2009;114(8):1545-52.

20. Zhou Q, Munger ME, Highfill SL, Tolar J, Weigel BJ, Riddle M, Sharpe AH, Vallera DA, Azuma M, Levine BL, et al. Program death-1 signaling and regulatory $T$ cells collaborate to resist the function of adoptively transferred cytotoxic T lymphocytes in advanced acute myeloid leukemia. Blood. 2010;116(14):2484-93.

21. Zhou Q, Munger ME, Veenstra RG, Weigel BJ, Hirashima M, Munn DH, Murphy WJ, Azuma M, Anderson AC, Kuchroo VK, et al. Coexpression of Tim-3 and PD-1 identifies a CD8+ T-cell exhaustion phenotype in mice with disseminated acute myelogenous leukemia. Blood. 2011;117(17):4501-10.

22. Norde WJ, Maas F, Hobo W, Korman A, Quigley M, Kester MG, Hebeda K, Falkenburg JH, Schaap N, de Witte TM, et al. PD-1/PD-L1 interactions contribute to functional T-cell impairment in patients who relapse with cancer after allogeneic stem cell transplantation. Cancer Res. 2011;71(15):5111-22.

23. Yang H, Bueso-Ramos C, Dinardo C, Estecio MR, Davanlou M, Geng QR, Fang Z, Nguyen M, Pierce S, Wei $Y$ et al. Expression of PD-L1, PD-L2, PD-1 and CTLA4 in myelodysplastic syndromes is enhanced by treatment with hypomethylating agents. Leukemia. 2014;28(6):1280-8.

24. Kong $Y$, Zhang J, Claxton DF, Ehmann WC, Rybka WB, Zhu L, Zeng $H$, Schell TD, Zheng H. PD-1(hi)TIM-3(+) T cells associate with and predict leukemia relapse in $\mathrm{AML}$ patients post allogeneic stem cell transplantation. Blood Cancer J. 2015;5:e330.

25. Schnorfeil FM, Lichtenegger FS, Emmerig K, Schlueter M, Neitz JS, Draenert R, Hiddemann W, Subklewe M. T cells are functionally not impaired in AML: increased PD-1 expression is only seen at time of relapse and correlates with a shift towards the memory T cell compartment. J Hematol Oncol. 2015;8:93.

26. Kong Y, Zhu L, Schell TD, Zhang J, Claxton DF, Ehmann WC, Rybka WB, George MR, Zeng $\mathrm{H}$, Zheng $\mathrm{H}$. T-cell immunoglobulin and ITIM domain (TIGIT) associates with CD8+ T-cell exhaustion and poor clinical outcome in AML patients. Clin Cancer Res. 2016;22(12):3057-66.

27. Shapiro-Shelef M, Lin Kl, McHeyzer-Williams LJ, Liao J, McHeyzer-Williams MG, Calame K. Blimp-1 is required for the formation of immunoglobulin secreting plasma cells and pre-plasma memory B cells. Immunity. 2003;19(4):607-20.

28. Martins G, Calame K. Regulation and functions of Blimp-1 in T and B lymphocytes. Annu Rev Immunol. 2008;26:133-69.

29. Shin H, Blackburn SD, Intlekofer AM, Kao C, Angelosanto JM, Reiner SL, Wherry EJ. A role for the transcriptional repressor Blimp-1 in CD8(+) T cell exhaustion during chronic viral infection. Immunity. 2009;31(2):309-20.

30. Parish IA, Marshall HD, Staron MM, Lang PA, Brustle A, Chen JH, Cui W, Tsui YC, Perry C, Laidlaw BJ, et al. Chronic viral infection promotes sustained Th1derived immunoregulatory IL-10 via BLIMP-1. J Clin Invest. 2014;124(8):3455-68.

31. Welsh RM. Blimp hovers over T cell immunity. Immunity. 2009;31(2):178-80.

32. Horn M, Geisen C, Cermak L, Becker B, Nakamura S, Klein C, Pagano M, Antebi A. DRE-1/FBXO11-dependent degradation of BLMP-1/BLIMP-1 governs C. elegans developmental timing and maturation. Dev Cell. 2014;28(6):697-710.

33. Zhu L, Ke Y, Shao D, Cui Y, Qiao A, Liu X, Fang F, Chang Y. PPARgamma co-activator-1alpha co-activates steroidogenic factor 1 to stimulate the synthesis of luteinizing hormone and aldosterone. Biochem J. 2010;432(3):473-83.

34. Gong D, Malek TR. Cytokine-dependent Blimp-1 expression in activated T cells inhibits IL-2 production. J Immunol. 2007;178(1):242-52. 
35. McClellan S, Slamecka J, Howze P, Thompson L, Finan M, Rocconi R, Owen L. mRNA detection in living cells: a next generation cancer stem cell identification technique. Methods. 2015;82:47-54.

36. Sallusto F, Lenig D, Forster R, Lipp M, Lanzavecchia A. Two subsets of memory $T$ lymphocytes with distinct homing potentials and effector functions. Nature. 1999;401(6754):708-12.

37. Sallusto F, Geginat J, Lanzavecchia A. Central memory and effector memory T cell subsets: function, generation, and maintenance. Annu Rev Immunol. 2004;22:745-63.

38. Moro-Garcia MA, Alonso-Arias R, Lopez-Larrea C. When aging reaches CD4+ T-cells: phenotypic and functional changes. Front Immunol. 2013;4:107.

39. Xu L, Zhang Y, Luo G, Li Y. The roles of stem cell memory T cells in hematological malignancies. J Hematol Oncol. 2015;8:113.

40. Kallies A, Xin A, Belz GT, Nutt SL. Blimp-1 transcription factor is required for the differentiation of effector CD8(+) T cells and memory responses. Immunity. 2009;31(2):283-95.

41. Calame K. Transcription factors that regulate memory in humoral responses. Immunol Rev. 2006;211:269-79.

42. Zhang Z, Liang L, Li D, Nong L, Liu J, Qu L, Zheng Y, Zhang B, Li T: Hypermethylation of PRDM1/Blimp-1 promoter in extranodal NKT-cell lymphoma, nasal type: an evidence of predominant role in its downregulation. Hematol Oncol. 2016. doi: 10.1002/hon.2362.

43. Martin-Arruti M, Vaquero M, Diaz de Otazu R, Zabalza I, Ballesteros J, Roncador G, Garcia-Orad A. BCl-2 and BLIMP-1 expression predict worse prognosis in gastric diffuse large B cell lymphoma (DLCBL) while other markers for nodal DLBCL are not useful. Histopathology. 2012;60(5):785-92.

44. Zhang T, Ma J, Nie K, Yan J, Liu Y, Bacchi CE, Queiroga EM, Gualco G, Sample JT, Orazi A, et al. Hypermethylation of the tumor suppressor gene PRDM1/Blimp-1 supports a pathogenetic role in EBV-positive Burkitt lymphoma. Blood Cancer J. 2014;4:e261.

45. Duckworth A, Glenn M, Slupsky JR, Packham G, Kalakonda N. Variable induction of PRDM1 and differentiation in chronic lymphocytic leukemia is associated with anergy. Blood. 2014;123(21):3277-85.

46. Hu WT, Liu JW, Liu HC, Wang TT. Expression of Blimp-1 mRNA in bone marrow mononuclear cells in multiple myeloma patients and its clinical significance]. Zhongguo shi yan xue ye xue za zhi. 2016;24(5):1443-8.

47. Hodge LS, Ziesmer SC, Yang ZZ, Secreto FJ, Gertz MA, Novak AJ, Ansell SM. $\mathrm{IL}-21$ in the bone marrow microenvironment contributes to IgM secretion and proliferation of malignant cells in Waldenstrom macroglobulinemia. Blood. 2012;120(18):3774-82.

48. Rutishauser RL, Martins GA, Kalachikov S, Chandele A, Parish IA, Meffre E, Jacob J, Calame K, Kaech SM. Transcriptional repressor Blimp-1 promotes CD8(+) $T$ cell terminal differentiation and represses the acquisition of central memory $\mathrm{T}$ cell properties. Immunity. 2009;31(2):296-308.

49. Shin HM, Kapoor VN, Guan T, Kaech SM, Welsh RM, Berg L. Epigenetic modifications induced by Blimp-1 regulate CD8(+) T cell memory progression during acute virus infection. Immunity. 2013;39(4):661-75.

50. Xin A, Masson F, Liao Y, Preston S, Guan T, Gloury R, Olshansky M, Lin JX, Li P, Speed TP et al. A molecular threshold for effector CD8 T cell differentiation controlled by transcription factors Blimp-1 and T-bet. Nature Immunol. 2016;17(4):422-32.

51. Collins $\mathrm{MH}$, Henderson AJ. Transcriptional regulation and T cell exhaustion. Curr Opin HIV AIDS. 2014;9(5):459-63.

52. Shankar EM, Che KF, Messmer D, Lifson JD, Larsson M. Expression of a broad array of negative costimulatory molecules and Blimp-1 in T cells following priming by HIV-1 pulsed dendritic cells. Mol Med. 2011;17(3-4):229-40.

53. Dohner H, Estey E, Grimwade D, Amadori S, Appelbaum FR, Buchner T, Dombret $H$, Ebert BL, Fenaux P, Larson RA, et al. Diagnosis and management of AML in adults: 2017 ELN recommendations from an international expert panel. Blood. 2017;129(4):424-47.

54. Kupsa T, Vasatova M, Karesova I, Zak P, Horacek JM. Baseline serum levels of multiple cytokines and adhesion molecules in patients with acute myeloid leukemia: results of a pivotal trial. Exp Oncol. 2014;36(4):252-7.

55. Lu P, Youngblood BA, Austin JW, Mohammed AU, Butler R, Ahmed R, Boss JM. Blimp-1 represses CD8 T cell expression of PD-1 using a feed-forward transcriptional circuit during acute viral infection. J Exp Med. 2014;211(3): 515-27.

56. Riches JC, Davies JK, McClanahan F, Fatah R, lqbal S, Agrawal S, Ramsay AG, Gribben JG. T cells from CLL patients exhibit features of T-cell exhaustion but retain capacity for cytokine production. Blood. 2013;121(9):1612-21.
57. Pauken KE, Wherry EJ. Overcoming T cell exhaustion in infection and cancer. Trends Immunol. 2015;36(4):265-76.

58. Crawford A, Angelosanto JM, Kao C, Doering TA, Odorizzi PM, Barnett BE, Wherry EJ. Molecular and transcriptional basis of CD4(+) T cell dysfunction during chronic infection. Immunity. 2014;40(2):289-302.

59. Morou A, Palmer BE, Kaufmann DE. Distinctive features of CD4+ T cell dysfunction in chronic viral infections. Curr Opin HIV AIDS. 2014;9(5):446-51.

60. Hwang S, Cobb DA, Bhadra R, Youngblood B. Blimp-1-mediated CD4 T cell exhaustion causes CD8 T cell dysfunction during chronic toxoplasmosis. J Exp Med. 2016;213(9):1799-818.

\section{Submit your next manuscript to BioMed Central and we will help you at every step:}

- We accept pre-submission inquiries

- Our selector tool helps you to find the most relevant journal

- We provide round the clock customer support

- Convenient online submission

- Thorough peer review

- Inclusion in PubMed and all major indexing services

- Maximum visibility for your research

Submit your manuscript at www.biomedcentral.com/submit 